\title{
Gastro-duodenal Crohn disease in a child presenting with cyclical vomiting
}

\author{
H M D Herath ${ }^{1}$, T Sekar ${ }^{2}$, Hemal de Silva ${ }^{3}$, Viraj Jayasinghe ${ }^{3}$, Shama Weerasinghe ${ }^{3}$, Ruwan Dissanayake ${ }^{3}$
}

Sri Lanka Journal of Child Health, 2011; 40(4): 183-184

(Key words: Gastro-duodenal; Crohn disease; child; cyclical vomiting)

\section{Introduction}

Crohn disease is a chronic inflammatory bowel disease which occurs rarely in Asian children. Gastro-duodenal Crohn disease is an even rarer entity, occurring only in $0.5-5 \%{ }^{1}$ of all patients. However, it remains an important cause for cyclical vomiting. According to Nugent and Roy diagnostic criteria, gastro-duodenal Crohn disease is diagnosed in the following situations $\mathbf{s}^{1,2}$.

1. Granulomatous inflammation of stomach/ duodenum with or without Crohn disease in the remaining gastrointestinal (GI) tract in the absence of other granulomatous disease.

2. Confirmed Crohn disease in GI tract and radiographic or endoscopic finding of diffuse inflammation of stomach or duodenum.

\section{Case report}

A 9 year old boy presented with recurrent cycles of vomiting since 7 years of age. Each vomiting spell lasted for 2-7 days, with 10-20 episodes of vomiting per day. This non projectile vomiting contained partially digested food of previous meal without bile staining. During last 6 months, vomiting became an almost daily symptom. He needed frequent hospital admissions to correct dehydration and electrolyte imbalance. Vomiting that persisted despite bowel resting, regular antiemetic and antacids, led to regular prescription of ondancetron. His weight dropped from $25^{\text {th }}$ centile to $<3^{\text {rd }}$ centile. His height velocity decreased. He had no diarrhoea, fever or erythema nodosum. Apart from two generalized tonic-clonic seizures he was well before the onset of vomiting. His weight was on $25^{\text {th }}$ centile while height was on $50^{\text {th }}$ centile. He was developmentally normal.

\section{${ }^{1}$ Senior Registrar in Paediatrics, ${ }^{2}$ Consultant Paediatrician, ${ }^{3}$ Registrar in Paediatrics, Lady Ridgeway Hospital, Colombo}

(Received on 14 December 2010: Accepted on 21 December 2010)
Prior to admission with daily vomiting, he had undergone a barium meal and follow-through, which was normal. Gastro-duodenoscopy had revealed pan gastritis. Biopsy from gastric mucosa was reported as superficial gastritis. He had been treated with several regimens of Helicobactor pylori treatment, with poor response. Among other medications that had been tried on him were flunarazine for migraine and sodium valproate for occipital lobe epilepsy.

His white cell count was $10 \times 10^{9} / \mathrm{L}$ (N-48,L-46, E-4), haemoglobin $9 \mathrm{~g} / \mathrm{dl}$, ESR $20 \mathrm{~mm}$ in the first hour and serum protein $29 \mathrm{mg} / \mathrm{dl}$. Blood picture showed a hypochromic microcytic anaemia. His serum ammonia and arterial blood gases were normal. Liver enzymes, serum bilirubin, serum creatinine and blood urea levels were within normal limits. CT scan of brain, done in the initial stage of illness, showed no evidence of a space occupying lesion.

Repeat upper GI endoscopy revealed diffuse inflammation of stomach and duodenum. There were no mucosal ridging, cobblestones or linear ulceration. Colonoscopy showed a prominent prolapsed ileocaecal valve. Duodenal biopsy reported focal flattening of villi and increased activity in lamina propria. Histology of ileocaecal valve showed mild to moderate crypt distortion; the lamina propria was oedematous with scattered polymorphs and chronic inflammation. CT enterography, video capsule endoscopy and $\mathrm{p}$ ANCA levels were not done. He was treated with prednisolone and azathioprine with dramatic improvement of symptoms.

\section{Discussion}

Crohn disease is a chronic inflammatory bowel disease of multifactorial pathogenesis. Genetic susceptibility has been mapped to genes that regulate immune response of gut such as NOD 2/ CARD 15, ATG-16U, and IL23R. Cigarette smoking, NSAIDS, and bacterial pathogens in gut are identified as triggering or exacerbating factors ${ }^{5}$. Triggering events lead to chronic inflammation of patchy distribution, architectural distortion and granuloma formation. Inflammation is mediated by Th 1 cytokines as IL-12 and TNF alpha ${ }^{4}$. 
Though any part of GI tract can be affected from mouth to anus, the location remains fairly constant in a given patient. Proximal Crohn disease comprises up to $5 \%$ of patients. Conversely, patients with symptoms pertaining to the rest of the bowel can have gastric or duodenal inflammation that is clinically insignificant. Clinical spectrum of gastroduodenal Crohn disease includes vomiting, early satiety, bloating, belching, epigastric pain and haematemesis. They can progress to have fistula formation or stricture formation.

Radiographic signs include mucosal nodularity, thickened folds and ulceration of gastric mucosa. Funnel shaped gastric antrum and duodenal bulb known as Ram's horn is a rare finding. Endoscopy and duodenal/gastric biopsy remain the gold standard of diagnosis. Macroscopic features comprise patchy inflammation, friability, cobblestones apthous ulcers and linear ulceration. Commonest histological finding is $H$. pylori negative patchy gastritis, with or without granuloma formation ${ }^{3}$. Histopatopathologic findings of gastro-duodenal Crohn disease are nonspecific and are confused with $H$. pylori infection, peptic ulcer disease, gastric lymphoma, tuberculosis, eosinophilic gastritis, and hypertrophic gastropathy. Therefore, diagnosis of proximal Crohn disease requires a high degree of clinical suspicion to establish Crohn disease in the remaining gut.

\section{References}

1. Issacs KL. Upper gastro-intestinal tract endoscopy in inflammatory bowel disease. Gastrointest Endosc Clin North Am 2002; 12: 451-62. http://dx.doi.org/10.1016/S1052-5157(02)00006-5

2. Van Hogezand RA, Witte AM, Veendaai RA, Wagtmans MJ, Lamers CB. Proximal Crohn disease: review of the clinicopathologic features and therapy. Inflamm Bowel Dis 2001; 7:328-37. http://dx.doi.org/10.1097/00054725-200111000$\underline{00010}$

3. Hommes DW, van Deventer SJ. Endoscopy in inflammatory bowel disease. Gastroenterology 2004; 126(6):1561-73. http://dx.doi.org/10.1053/j.gastro.2004.03.023

4. Vermeire S, Rutgeerts P. Current status of genetics research in inflammatory bowel disease. Genes Immun 2005; 6(8):637-45.

5. Rubin, DT, Hanauer SB.. Smoking and inflammatory bowel disease. Eur. J. Gastroenterol Hepatol 2000; 12:855-62. http://dx.doi.org/10.1097/00042737-200012080$\underline{00004}$ 